\title{
Comparative life cycle assessment of astaxanthin production with Haematococcus pluvialis in different photobioreactor technologies
}

\author{
Cristina Onorato*, Christine Rösch \\ Institute for Technology Assessment and Systems Analysis (ITAS), Karlsruhe Institute of Technology (KIT), Hermann-von-Helmholtz-Platz 1, 76344 Eggenstein- \\ Leopoldshafen, Germany
}

\author{
Keywords: \\ Microalgae \\ LCA \\ Astaxanthin \\ H. pluvialis
}

\begin{abstract}
A B S T R A C T
Haematococcus pluvialis is one of the most abundant sources of natural astaxanthin when compared with other microorganisms, and has attracted the interest of the market thanks to its health benefits. We investigated the environmental performance of the cultivation of $H$. pluvialis and the astaxanthin production processes through a comprehensive Life Cycle Analysis (LCA). This study compares the potential environmental impact of three photobioreactors (PBR) available on the market: the flat panel airlift, the green wall panel, and the unilayer horizontal tubular PBR . These systems have different technical settings: the flat panel airlift has a double-sided light emitting diode (LED) illumination system and is placed inside a building; the green wall panel is located outside and equipped with one-side LED lighting; the unilayer horizontal tubular is placed outside without any artificial lighting. Two different functional units were considered: one $\mathrm{kg}$ of $\mathrm{H}$. pluvialis ( $80 \% \mathrm{dw})$ and $1 \mathrm{~kg}$ of astaxanthin. Where $1 \mathrm{~kg}$ of astaxanthin was selected as functional unit, as the content of astaxanthin in the biomass is low, the system expansion method was applied.

The LCA results, based on original data from pilot-scale production, indicate that the system design, and the energy mix used have a significant environmental impact, due to differences in algae productivities and energy demand. For indoor systems, even with light-emitting diodes (LED), the energy demand for lighting is the main contributor to climate change. This contribution decreases significantly if the share of renewable energy increases. In the case of the green wall panel another main climate change contributor is the material used for the diode production, including tin and molybdenum. Although the astaxanthin yield is higher in the flat panel airlift and green wall panel, electricity production systems still const tute an environmental burden. For this reason, the system with the lowest environmental impact is the unilayer horizontal tubular, i.e. the photobioreactor where no artificial light is used.
\end{abstract}

\section{Introduction}

Microalgae and cyanobacteria constitute a large family of photosynthetic organisms that are a natural source of high-value compounds for the nutraceutical, cosmetic, pharmaceutical and food industries $[1,2]$. In recent decades, the microalgae field has been widely investigated for several applications, but only that covering the production of high-value nutrition ingredients has achieved commercial success [3]. Under stress conditions (e.g. nutrient deprivation and high radiation), several microalgae strains are able to produce interesting compounds such as lipids or carotenoids [4]. Among the carotenoids, astaxanthin and $\beta$-carotene are well-known compounds, characterized by antioxidant, photoprotection and provitamin A activity, which are widely used in the cosmetic, nutraceutical and feed sectors to improve the commercial value of animals and animal product $[5,6]$.
Astaxanthin is a pink ketocarotenoid synthesized by some algae species, plants, and fungi. It has strong antioxidant properties with the ability to neutralize free radicals, giving benefits to human health [7]. The commercial astaxanthin market is dominated by synthetic astaxanthin. The total market value is over $\$ 240$ million per year and the astaxanthin market price is around $\$ 2000$ per $\mathrm{kg}$ [5]. Synthetic astaxanthin contains different isomers from the natural product [8], and the main producers are BASF and Hoffman-La Roche. Since there are concerns regarding the safety of this synthetic compound when consumed directly by humans, natural astaxanthin is starting to be a preferred choice [5]. Astaxanthin is found widely in aquatic animals and some other organisms, but its de novo synthesis is limited to several bacteria, fungi, algae and plants. The most common source for natural astaxanthin production is the green microalgae Haematococcus pluvialis, which is able to accumulate large amounts of astaxanthin under 
nutrient deprivation and high irradiance (up to $4 \%$ under natural light and up to $8 \%$ under artificial light [9]). Some recent studies focus on the possibility of increasing astaxanthin accumulation through mutagenesis strategies [4].

$H$. pluvialis is usually cultivated in two kinds of systems: open raceway ponds (ORPs) and closed photobioreactors (PBRs). In both systems, the cells grow photoautotrophically, i.e. with a non-organic carbon source as $\mathrm{CO}_{2}[5,10]$. Both techniques are adopted industrially, but more than $90 \%$ of the biomass cultivated globally is produced in ORPs [11]. ORPs are less expensive and easier to operate, but since they are open systems, they are characterized by high evaporation losses, high contamination risks and low volumetric productivity, which causes an energy-intensive downstream process. Moreover, ORPs can be used only in areas with appropriate climate conditions. Closed systems do not suffer from these problems but are more expensive to build $[10,12]$. Several PBRs have been investigated in recent years, but mainly for small-scale application [12]. Together with high cost, the other main problem related to the closed PBR is scalability. For this reason, several parameters have been improved in closed PBRs to increase productivity, including the intensification of the mixing, the use of artificial light and increase of the external surface. Currently, the most used PBRs are the Flat Panel Airlift (FPA), the Green Wall Panel (GWP) PBR, and the tubular (UHT) PBR. These PBRs show different characteristics, including the materials used and their configuration, but even though PBRs have been widely investigated, their design still needs to be improved to consider both technological and environmental aspects in order to be both economically and environmentally feasible [12].

Despite the numerous advantages of microalgae, including the use of marginal land which avoids competition with food production, and the potential to use wastewater as a nutrient source, other aspects need to be improved in order to make their production environmentally friendly. Greenhouse gas emissions due to energy consumption during the production chain are one of the main issues for microalgae application. For this reason, life cycle assessment (LCA) can be used as a tool for decision-making during process design. Indeed, environmental impact analysis is essential for the sustainable development of the industry.

Several studies have evaluated the potential environmental impact of algae cultivation [10,13-15] for biofuel production [14,16-22] or added value compounds production [10,23,24]. However, all of these are based on lab-scale/small pilot primary data, or data from literature and linear extrapolation based on lab-scale experiment. In general, none of these studies considers a larger pilot-scale production that includes the processes that are present at an industrial scale, where primary data are used and artificial light is provided by using lightemitting diodes (LEDs). Moreover, there is no clear environmental comparison for the production of a specific product with the same algal strain using different PBR technologies, considering different production sites, which sometimes require the application of artificial light to replace the lack of natural light, in particular if the PBRs are housed in a building in order to achieve year-round production.

Against this background, this study bridges this knowledge gap by providing a comparative life cycle assessment (LCA) of the three most relevant commercialized PBRs for the production of astaxanthin. Three companies producing/testing the PBRs in the framework of the EU project ABACUS provided the information and data for the LCA. Data regarding the Flat Panel Airlift (FPA) were provided by Subitec Gmbh [25], the Unilayer Horizontal Tubular PBR (UHT-PBR) by A4F [26], and the Green Wall Panel (GWP) by Microphyt [27]. The three PBRs are located in different production sites. The FPA is located in Stuttgart, Germany, housed in a building where the PBR is equipped with doublesided lighting. Both the GWP (Montpellier, France) and the UHT (Lisbon, Portugal) are located outside. While the GWP has installed onesided lighting, the UHT does not apply any lighting. This work aims to assess the potential environmental impact of natural astaxanthin production with $H$. pluvialis in a novel way, in close cooperation with the technology designers and users, by applying large pilot-scale information. Through this approach, reliable and comprehensible guidelines and recommendations can be provided to engineers and decision-makers in politics and industry, providing highly beneficial support for further development and improvement of the existing technologies and production processes.

\section{Materials and methods}

For the LCA, the three most relevant commercial available PBR systems available on the market were selected. For modeling and assessing the environmental impacts, information and data were provided by three companies for their installations at different European sites (Germany, France and Portugal). While data at a production scale of 93 $\mathrm{m}^{3}$ were provided from Subitec and A4F $[25,26]$ for FPA and UHT, the data for the GWP were only available at a smaller scale $\left(0.1 \mathrm{~m}^{3}\right)$ [27], and therefore had to be upscaled to a volume of $92 \mathrm{~m}^{3}$ to make the GWP comparable to the other two PBRs. The process of astaxanthin production with $H$. pluvialis, illustrating the main inputs and outputs, is depicted in Fig. 1. The main production steps are the cultivation and harvesting of the algae and the extraction of astaxanthin. The cultivation stage starts with the inoculation phase, followed by two main phases. The green phase is when sufficient nutrients are provided to the

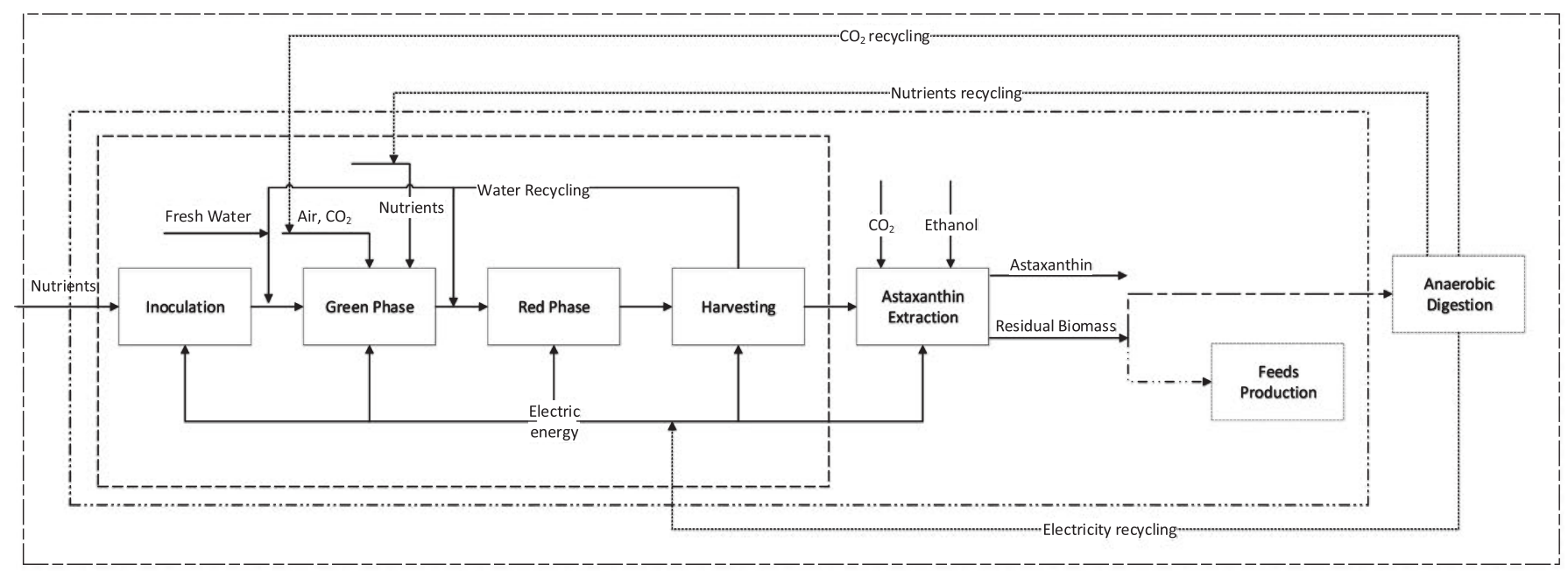

Fig. 1. Astaxanthin production process with main inputs and outputs. 
microalgae to promote cell growth and division. The red phase, also called starvation phase, is when the absence of nutrients, in particular nitrogen, promotes astaxanthin accumulation in the algae cells. During the inoculation phase the algae culture is prepared and grown to a high density and then the volume is increased gradually by diluting the dense cultures in successive stages to provide enough inoculum to start the cultivation process in the PBRs. Harvesting of the algae is performed through different processes in serial. In this study, the technologies of filtration, centrifugation and spraydryer were selected in order to obtain algal biomass with high dry matter content of $80-85 \%$ dry weight (dw). After the drying process, the astaxanthin is extracted using $\mathrm{CO}_{2}$ in supercritical condition $\left(60{ }^{\circ} \mathrm{C}\right.$ and $300 \mathrm{bar}$ ) with ethanol as co-solvent. After the extraction, the residual biomass can be used as animal feed or for energy production, considering different thermo-chemical or biological conversion technologies. In this work, we focus on anaerobic digestion, as this process is more mature and proven than others (such as hydrothermal liquefaction).

When the residual algal biomass (after astaxanthin extraction) is used as feedstock for anaerobic digestion, three main products are produced: $\mathrm{CO}_{2}, \mathrm{CH}_{4}$ (converted in electricity), and a nutrient rich digestate. Theoretically, all three products can be recycled and used as material and energy input for the astaxanthin production system. The other option is to produce animal feed. A third option can also be outlined, which is the direct use of harvested $H$. pluvialis. Since the amount of astaxanthin in $H$. pluvialis is low, the product chain can be interrupted after the harvesting phase, obtaining dry biomass (80-85\% $\mathrm{dw}$ ) with a high content of astaxanthin that can be directly commercialized. These three options will be analysed from the life cycle perspective and are shown in Fig. 1, characterized by the dashed lines.

\subsection{Flat Panel Airlift (FPA) system description}

The cultivation phase of $H$. pluvialis in the FPA photobioreactor with a total final volume of $93 \mathrm{~m}^{3}$ is constituted by several stages: preparation of the culture, culture upscaling, green phase and red phase. The details for each stage are specified in Table 1.

The FPA cultivation system is housed in a building in Stuttgart (Germany), and each side is illuminated by LEDs. The LEDs are fixed in aluminum bars. Each bar was assumed to be $2 \mathrm{~m}$ long with a height of $10 \mathrm{~cm}$ and a thickness of $2 \mathrm{~cm}$. The weight of one bar is $3.7 \mathrm{~kg}$; the aluminum and LED material present in each bar is $864 \mathrm{~g}$ and $2.836 \mathrm{~kg}$ respectively. The amount of nutrients, $\mathrm{CO}_{2}$, air, bleach needed for the process, electricity consumption for all the equipment and LEDs were provided. A ventilation system is used to maintain the temperature of the room and thereby keep the culture constant. The energy consumption of the ventilation system was included in the data. All data were provided by Subitec GmbH [25].

\subsection{Unilayer Horizontal Tubular (UHT) system description}

The cultivation phase of $H$. pluvialis in the UHT-photobioreactor with a total final volume of $93 \mathrm{~m}^{3}$ is constituted by four increasingly large reactors: $0.28 \mathrm{~m}^{3}$ inoculation, $2.2 \mathrm{~m}^{3}$ inoculation, green phase and red phase. The details for each stage are depicted in Table 2 .

The UHT-PBR is based in Lisbon (Portugal) and is placed outside. The amount of nutrients, $\mathrm{CO}_{2}$, air, bleach needed for the process, electricity consumption for all the equipment were provided. The cooling of the culture is performed by spraying the tubes with fresh water. The water and electricity consumption associated with the cooling process were included in the data. All data were provided by A4F GmbH [26].

\subsection{Green Wall Panel (GWP) system description}

Since only data for the small-scale GWP $\left(0.1 \mathrm{~m}^{3}\right)$ were available, an upscaling methodology based on that developed by M. Tredici et al. [28], was implemented. The GWP cultivation phase was assumed to be constituted by an inoculation phase, a green phase, and a red phase. In the small-scale configuration, the volume rate between the green phase and the red phase was equal to $1 / 3$. The same proportion was assumed for a larger scale. The reactor volume for the red phase needs to be larger than the green phase in order to decrease the algae concentration from the green phase and have more light per single cell in order to accelerating astaxanthin production.

Assuming the length of the GWP equal to $48 \mathrm{~m}$, the thickness $4.8 \mathrm{~cm}$, and the height $0.7 \mathrm{~m} \mathrm{[28]}$, the number of GWPs that give a volume of $93 \mathrm{~m}^{3}$ was estimated. The characteristics of each stage are depicted in Table 3. The plant has been divided into 4 modules of 15 GWP of $23 \mathrm{~m}^{3}$ each; one module constitutes the green phase, and three modules the red phase. For each module, a circulation pump and a heat exchanger have been selected. A volume of $1 \mathrm{~m}^{3}$ has been assumed for the inoculum. The GWP system is located outside, in Montpellier (France), and light-emitting diodes (LED) bar are allocated to one side of the panel to provide artificial light. Considering the length of the GWP, the number of bars needed was estimated. The energy consumption associated with one LED bar is $0.08 \mathrm{~kW}$. The LEDs' characteristics were assumed to be the same as for the FPA-PBR.

\subsubsection{Air and $\mathrm{CO}_{2}$ supply}

In this study, the amount of air and $\mathrm{CO}_{2}$ required by the small system was considered, and upscaled linearly. The amount needed for $93 \mathrm{~m}^{3}$ was $79.35 \mathrm{Nm}^{3} / \mathrm{h}$ for the red phase, and $26.45 \mathrm{Nm}^{3} / \mathrm{h}$ for the green phase. According to the datasheet of the blowers provided by MAPRO [29], a blower named CL 18/01 with a flow rate of $106 \mathrm{~m}^{3} / \mathrm{h}$ was assumed. The selected flow rate should be sufficient to avoid sedimentation of $H$. pluvialis and remove the oxygen produced by photosynthesis.

Table 1

Main parameters of $H$. pluvialis cultivation in a Flat Panel Airlift (FPA) photobioreactor with $93 \mathrm{~m}^{3}$.

\begin{tabular}{|c|c|c|c|c|c|}
\hline \multirow[t]{2}{*}{ PBR configuration } & \multicolumn{5}{|c|}{ FPA } \\
\hline & Unit & Culture preparation & Culture upscaling & Green phase & Red phase \\
\hline Volume & $\mathrm{m}^{3}$ & 0.006 & 0.0275 & 0.18 & 0.18 \\
\hline Number of FPA & - & 1 & 4 & 90 & 420 \\
\hline Number of LEDs each panel & - & - & - & 6 & 10 \\
\hline Total number of LEDs & - & - & - & 540 & 4200 \\
\hline Occupied land & $\mathrm{m}^{2}$ & 13 & 28 & 200 & 860 \\
\hline Total occupied land & ha & - & & & \\
\hline \multicolumn{6}{|l|}{ Operation parameters } \\
\hline Cultivation period & Days & 310 & 304 & 310 & 225 \\
\hline Amount of biomass produced in one year & $\mathrm{kg}$ & 0.7 & 13.6 & 4957.2 & 12,758 \\
\hline Biomass concentration & $\mathrm{g} / \mathrm{l}$ & 3.5 & 5.9 & 5 & 3.75 \\
\hline Volumetric biomass productivity & g/l/day & 0.37 & 0.4 & 1 & 0.75 \\
\hline
\end{tabular}


Table 2

Main parameters of $H$. pluvialis cultivation in a Unilayer Horizontal Tubular (UHT) photobioreactor with $93 \mathrm{~m}^{3}$.

\begin{tabular}{|c|c|c|c|c|c|}
\hline \multirow[t]{2}{*}{ PBR configuration } & \multicolumn{5}{|c|}{ UHT } \\
\hline & Unit & Inoculation $0.28 \mathrm{~m}^{3}$ & Inoculation $2.2 \mathrm{~m}^{3}$ & Green phase & Red phase \\
\hline Volume & $\mathrm{m}^{3}$ & 0.28 & 2.2 & 18 & 71.52 \\
\hline Number of reactors & - & 1 & 1 & 1 & 1 \\
\hline Occupied land & $\mathrm{m}^{2}$ & 8 & 61 & 497 & 1794 \\
\hline Total occupied land & ha & - & & & \\
\hline \multicolumn{6}{|l|}{ Operation parameters } \\
\hline Cultivation period & Days & 330 & 330 & 330 & 330 \\
\hline Amount of biomass produced in one year & $\mathrm{kg}$ & 33 & 259 & 2109 & 3454 \\
\hline Biomass concentration & $\mathrm{g} / 1$ & 2.15 & 2.14 & 2.13 & 0.88 \\
\hline Volumetric biomass productivity & g/l/day & 0.32 & 0.32 & 0.32 & 0.07 \\
\hline
\end{tabular}

Table 3

Main parameters of $H$. pluvialis cultivation in a Green Wall Panel (GWP) photobioreactor with $93 \mathrm{~m}^{3}$.

\begin{tabular}{|c|c|c|c|c|}
\hline \multirow[t]{2}{*}{ PBR configuration } & \multirow[b]{2}{*}{ Unit } & \multicolumn{3}{|c|}{ GWP } \\
\hline & & Inoculation & Green phase & Red phase \\
\hline Volume & $\mathrm{m}^{3}$ & 1 & 23 & 69 \\
\hline Height & $\mathrm{m}$ & 0.7 & 0.7 & 0.7 \\
\hline Length & $\mathrm{m}$ & 32 & 48 & 48 \\
\hline Thickness & $\mathrm{cm}$ & 4.8 & 4.8 & 4.8 \\
\hline LDPE thickness & $\mu \mathrm{m}$ & 300 & 300 & 300 \\
\hline Number of GWP & - & 1 & 15 & 46 \\
\hline Number of LEDs each panel & - & 15 & 24 & 24 \\
\hline Number of LEDs & - & 15 & 360 & 1104 \\
\hline Occupied land (considering $1 \mathrm{~m}$ distance) & $\mathrm{m}^{2}$ & 1 & 704 & 2259 \\
\hline Total occupied land & ha & & 0.3 & \\
\hline \multicolumn{5}{|l|}{ Operation parameters } \\
\hline Cultivation period & Days & 310 & 310 & 225 \\
\hline Amount of biomass produced in one year & $\mathrm{kg}$ & 62 & 2781 & 3260 \\
\hline Biomass concentration & $\mathrm{g} / 1$ & 0.33 & 4.83 & 1.16 \\
\hline Volumetric productivity & g/l/day & 0.2 & 0.39 & 0.21 \\
\hline
\end{tabular}

\subsubsection{Cooling system}

For the small-scale system, no cooling was considered. Based on M. Tredici et al. [30], cooling is needed for around 5-6 months per year. The GWP system is located in Montpellier, a place with suitable conditions for algal growth regarding light radiation and temperature. Besides looking for a suitable climate for algae growth, other aspects such as the availability of water and land should be taken into consideration and improved to reduce the water and the land demand as well as possible direct land use change [31]. A characterization of suitable land [32] is therefore fundamental to optimize the microalgae production system. In the south of France, these conditions were assessed by the company cultivating the strains [27]. In this area, the climate and yearly average temperature can be assumed to be similar to that of the coast of Tuscany, where Tredici et al. conducted their studies $[28,30]$. Assuming that the system is located on the coast, seawater can be used to cool the PBR during summertime. The seawater was assumed to be available near to the plant at an average temperature of $20^{\circ} \mathrm{C}$ and pumped with submersible pumps through the heat exchangers. Once used, the water is sent back to the sea, since the increase in temperature is low. In this way, water consumption related to the cooling could be disregarded. Details regarding the equipment for the cooling system are reported in Table 5.

In order to calculate the amount of refrigerant needed for cooling, the energy balance was evaluated (Eq. (1)).

$\mathrm{Q}_{\text {cool }}=\mathrm{Q}_{\text {irr }}+\mathrm{Q}_{\mathrm{LED}}-\mathrm{Q}_{\text {conv }}$

where $\mathrm{Q}_{\text {cool }}$ is the thermal power to be dissipated $\left(\mathrm{W} / \mathrm{m}^{2}\right), \mathrm{Q}_{\text {irr }}$ is the irradiance $\left(W / \mathrm{m}^{2}\right), Q_{\mathrm{LED}}$ is the thermal power dissipated from the LED $\left(\mathrm{W} / \mathrm{m}^{2}\right)$, and $\mathrm{Q}_{\text {conv }}$ is the thermal power exchanged between the panel and the environment $\left(\mathrm{W} / \mathrm{m}^{2}\right)$. The thermal power related to the evaporation and the radiative effect from the panel towards the environment was neglected. The temperature of the culture was assumed to be constant at $30{ }^{\circ} \mathrm{C}$. Above this temperature, the algae cannot survive, and thus cooling needs to be started. At higher temperatures, the cessation of cell division can occur, with a consequent increase in the cell size and early production of astaxanthin [5]. Conversely, at low irradiance levels, light is limiting productivity and the growth rate is limited due to the lack of light energy [33]. The optimal growth temperature for $\mathrm{H}$. pluvialis is between 25 and $28^{\circ} \mathrm{C}$. Other strains can have a different optimal growth temperature. For instance, Gharagozloo et al. [33] reported lower values $\left(21.5-23.5{ }^{\circ} \mathrm{C}\right)$ for Nannochloropsis, values that were confirmed by the performed experiments. Another important parameter affecting algal productivity is the biomass loss through respiration during night time. This parameter is affected by different factors as water temperature and light exposure before the dark period [34]. In the case of the GWP, this was minimized by artificial illumination and temperature control. Regarding the $Q_{\text {irr }}$, data from the European Commission's Photovoltaic Geographical Information System [35] were used considering 6 months of operation, from April to September. The demand for coolant was calculated considering the maximum temperature picks in order to prevent a decrease in productivity or even breakdown of the culture. Regarding the $\mathrm{P}_{\text {conv }}$, it was expressed as [36]:

$\mathrm{Q}_{\text {conv }}=\mathrm{L} * \mathrm{~h} *$ ho $*(\mathrm{Tw}-\mathrm{Tair})$

where $\mathrm{L}$ is the length of the panel (m), $\mathrm{h}$ the height (m), ho is the convective coefficient $\left(\mathrm{W} / \mathrm{m}^{2} / \mathrm{C}\right), \mathrm{Tw}$ is the temperature of the wall (equal to $30^{\circ} \mathrm{C}$ ) and Tair is the air temperature estimated from the EC Photovoltaic Geographical Information System [35]. 
The convective coefficient was estimated considering the properties of the air. $Q_{\text {LED }}$ was calculated assuming that $15 \%$ of the power of the LEDs radiates the culture (increasing its temperature).

Knowing $\mathrm{Q}_{\text {cool }}$, the amount of refrigerant was estimated $\left(\mathrm{M}_{\text {cool }}\right)$ as:

$\mathrm{M}_{\text {cool }}=\mathrm{Q}_{\mathrm{cool}} *\left(\mathrm{cp}_{\mathrm{cool}} * \mathrm{DT}\right)$

assuming a difference in temperature (DT) of $10{ }^{\circ} \mathrm{C}$ of the refrigerant between the inlet and the outlet. Knowing the $\mathrm{M}_{\text {cool }}$, the flow rate of the culture $\left(\mathrm{M}_{\text {algae }}\right)$ was calculated, and therefore the pump was selected and the shell and tubes of the heat exchanger were designed.

\subsection{Downstream process (algae harvest and drying)}

The downstream process, comprising harvesting and drying of $H$. pluvialis, has been modeled based on primary and literature data. For industrial application, several processes in series were identified as a possible solution. In particular, filtration centrifugation and spraydrying are the processes that give the best performances [37].

Based on experimental data $[25,38]$, we assumed that $18 \%$ of the culture is harvested on a daily basis. This means that $15 \mathrm{~m}^{3} /$ day, $12.5 \mathrm{~m}^{3} /$ day and $11.9 \mathrm{~m}^{3}$ /day are harvested for the FPA, GWP and UHT respectively, and therefore 11.8 metric tons $(81 \% \mathrm{dw}), 3$ metric tons $(84 \% \mathrm{dw})$ and 3.2 metric tons $(83 \% \mathrm{dw})$ of red algae are harvested in one year using the FPA, GWP and UHT technology respectively. For the FPA and GWP, literature data were considered to estimate the energy consumption of filtration and centrifugation processes [37]. Regarding the UHT, primary data were provided. For the spraydryer, literature data were considered for all three systems. The culture from the red phase is circulated to the spiral wound membrane module equipped with microfiltration membranes. A maximum output of $1.5-10 \%$ of solids can be achieved from the filtration process with a biomass recovery of $99 \%$ and energy consumption of $0.8-2.51 \mathrm{kWh} / \mathrm{m}^{3}$ of permeate [37]. It is assumed that the permeate received after the filtration process is constituted mainly by water and can be recycled back to the green and red phases without any pretreatment. The retentate is sent to the centrifuge (recovery of $90 \%$ ) in order to obtain a paste with a maximum solid output concentration of $10-20 \%$ dry weight (dw). After that, a spraydryer $(\mathrm{R}=99 \%)$ is used to obtain a paste with $80-85 \% \mathrm{dw}$. The loss of water that occurs during the drying process was disregarded.

The red powder obtained after the drying process can be used as animal feed, taking advantage of the other valuable feed compounds present in the algae. If pure astaxanthin is the target product, the extraction step needs to be added to the production chain.

\subsection{Extraction of astaxanthin}

Several methodologies can be applied for astaxanthin extraction. Supercritical fluid extraction (SFE) is a modern and widely accepted method to recover high-value compounds from microalgae that are designated to the nutraceutical and pharmaceutical sector [39]. In this methodology, a fluid in supercritical condition is able to extract the compounds because of its physicochemical properties that are between

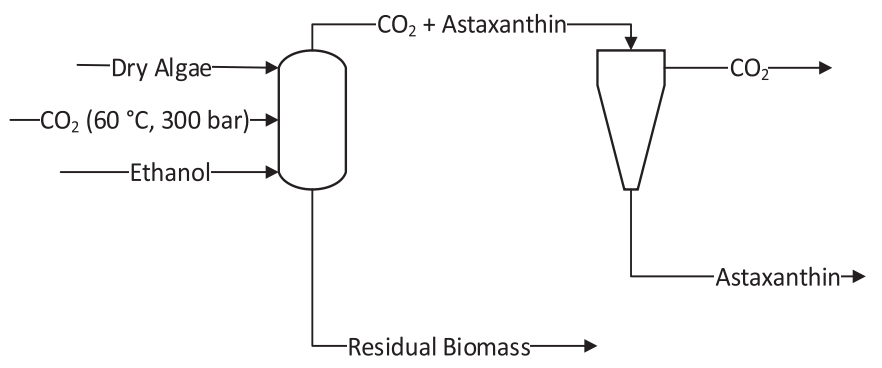

Fig. 2. Process Flow Diagram (PFD) of the astaxanthin extraction process. those of a liquid and a gas. Carbon dioxide is the most used fluid due to its critical pressure and temperature $\left(31.1^{\circ} \mathrm{C}, 7 \mathrm{MPa}\right)$, which are relatively low and can be easily removed at ambient condition thanks to its gas behavior [40]. Moreover, due to the low critical temperature, the degradation of valuable substances can be prevented [7]. Several studies have been performed to exploit the best extraction conditions with $\mathrm{CO}_{2}$ [39].

Based on this literature review, in this study, we assume to extract astaxanthin at $60{ }^{\circ} \mathrm{C}$ and 300 bar with $9.4 \%$ of ethanol as co-solvent (see Fig. 2).

In the papers reviewed, the final product after the extraction is an oleoresin containing $10-20 \%$ of astaxanthin [10]. Other authors assume that the pigment can be isolated as a pure substance (95-100\%) [40]. In this work, we assume that we can achieve pure astaxanthin (second option).

Since only lab-scale data for the extraction were available, this stage was modeled using literature [40-42]. In particular, the extraction process was modeled in two stages: extraction, and separation of the product. Regarding the extraction, $\mathrm{CO}_{2}$ in supercritical condition was used $\left(60^{\circ} \mathrm{C}\right.$ and $\left.300 \mathrm{bar}\right)$. A solvent/feed ratio equal to $20.12 / 1(\mathrm{~kg} / \mathrm{kg})$ was considered [40]. As co-solvent, ethanol was used, and a percentage volume of ethanol/ $\mathrm{CO}_{2}$ equal to $9.4 \%$ was assumed. For electricity consumption and the material of the equipment, the values calculated by P. Pérez-López et al. [10] were used and adapted to the case.

\subsection{Life cycle assessment methodology}

The life cycle assessment (LCA) methodology was used to evaluate the potential environmental impact of the three cultivation systems. The life cycle perspective allowed us to assess the environmental performance of all the processes required to produce the final product, from the acquisition of the raw materials, through their production and use stages, to the final disposal. The structure of the LCA is standardized by the ISO 14040 and 14044 standards, and consists of four phases: the goal and scope definition, the inventory analysis, the impact assessment, and the interpretation of the results $[43,44]$. The study also aimed at identifying the main hotspots that increase the environmental impact of this technology, giving some suggestions for future improvements.

\subsubsection{Goal and scope of the study}

The goal and scope of this study are to evaluate the potential environmental impact of three different photobioreactors located in three different regions with/without artificial light for the production of $H$. pluvialis with $80-85 \% \mathrm{dw}$ or astaxanthin during a period of one year. Two processes with different final products were analysed: the production of $H$. pluvialis with $80 \% \mathrm{dw}$ (Fig. 3) and the production of astaxanthin (Fig. 1). As a functional unit (FU), $1 \mathrm{~kg}$ of dried biomass was selected in the first case, and $1 \mathrm{~kg}$ of astaxanthin in the second case. These FUs were selected in order to compare the results with those present in the literature. The life cycle inventory and impact assessment methodology were therefore in each case referred to the selected FUs. The product system and the system boundaries include all the stages that affect the production chain. For each stage, energy and mass balances have been performed.

\subsubsection{Inventory analysis}

The inventory analysis focused on the collection of information about the physical and energy flows in terms of input of resources, material and products, and the output of emissions, waste and valuable products. For the foreground system, primary data were used for the FPA and UHT technology. The parameters related to the GWP were upscaled starting from data provided by A4F $\mathrm{GmbH}$, and Microphyt Gmbh [26,27] for the small system $\left(0.1 \mathrm{~m}^{3} \mathrm{GWP}\right)$. Data regarding the downstream and the extraction process were obtained from literature or experiments. The geometric and average operating parameters of each 


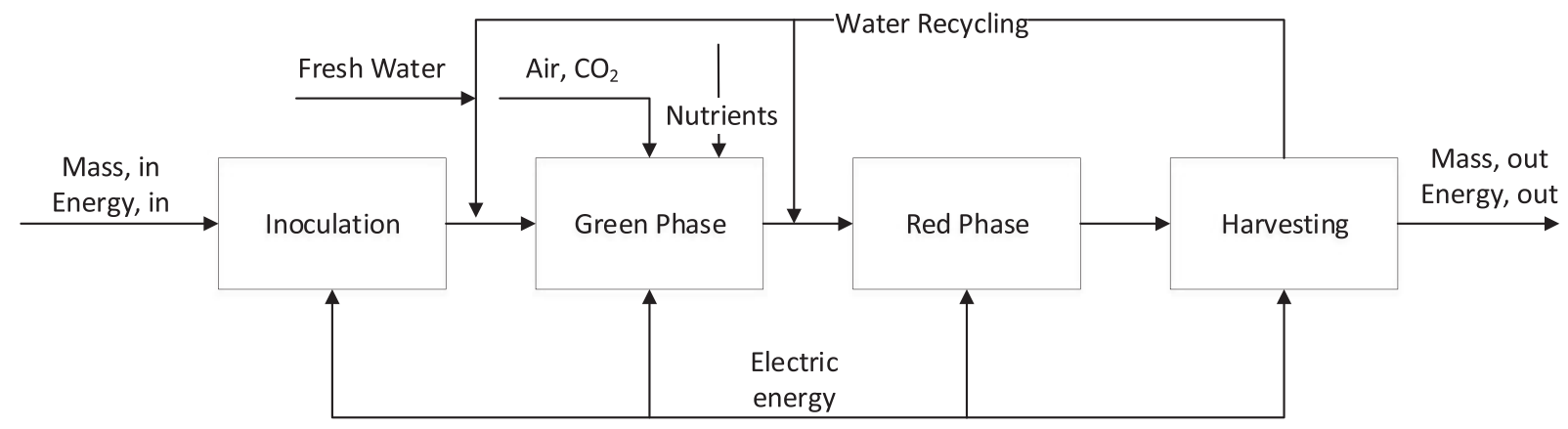

Fig. 3. Product system for the production of $1 \mathrm{~kg}$ of $H$. pluvialis.

Table 4

Life Cycle Inventory (LCI) of three different photobioreactor (Flat Panel Airlift (FPA), Green Wall panel (GWP) and Unilayer Horizontal Tubular (UHT)) on a yearly base.

\begin{tabular}{|c|c|c|c|c|}
\hline Reactor configuration & Unit & Flat panel airlift & Green wall panel & Unilayer horizontal tubular \\
\hline \multicolumn{5}{|l|}{ Geometrical parameter } \\
\hline Volume & $\mathrm{m}^{3}$ & 93 & 93 & 93 \\
\hline Occupied land & ha & 0.1 & 0.3 & 0.24 \\
\hline Number of LEDs & & 4740 & 1479 & - \\
\hline \multicolumn{5}{|l|}{ Operational parameter } \\
\hline Air & $\mathrm{Nm}^{3} /$ year & $5.62 \mathrm{E}+06$ & $5.39 \mathrm{E}+05$ & - \\
\hline $\mathrm{CO}_{2}$ & $\mathrm{~kg} /$ year & $8.87 \mathrm{E}+04$ & $1.87 \mathrm{E}+05$ & $1.76 \mathrm{E}+04$ \\
\hline Lighting & kWh/year & $3.56 \mathrm{E}+06$ & $6.91 \mathrm{E}+05$ & - \\
\hline Electricity for the process & $\mathrm{kWh} /$ year & $1.76 \mathrm{E}+05$ & $3.27 \mathrm{E}+05$ & $6.30 \mathrm{E}+04$ \\
\hline Nitrogen & $\mathrm{kg} /$ year & $3.76 \mathrm{E}+02$ & $2.90 \mathrm{E}+02$ & $2.33 \mathrm{E}+02$ \\
\hline Phosphate & $\mathrm{kg} /$ year & $2.65 \mathrm{E}+02$ & $1.25 \mathrm{E}+02$ & $2.55 \mathrm{E}+01$ \\
\hline Water for the culture & $\mathrm{kg} /$ year & $3.12 \mathrm{E}+02$ & $3.99 \mathrm{E}+03$ & $4.06 \mathrm{E}+02$ \\
\hline Water for cooling & $\mathrm{m}^{3} /$ year & - & - & $5.16 \mathrm{E}+03$ \\
\hline Water for cleaning & $\mathrm{m}^{3} /$ year & $4.42 \mathrm{E}+03$ & $1.81 \mathrm{E}+03$ & $2.76 \mathrm{E}+02$ \\
\hline Productivity (green phase) & $\mathrm{m}^{3} /$ year & 1 & 0.39 & 0.32 \\
\hline Productivity (red phase) & g/L/day & 0.75 & 0.21 & 0.07 \\
\hline Cultivation period & days & $310-225$ & $310-225$ & 330 \\
\hline
\end{tabular}

reactor are described in Table 4. Table 4 gives detailed information for the PBR systems to cultivate $H$. pluvialis during one year. In particular for FPA and GWP, it was assumed to have a green phase of 310 days and a red phase of 225 days based on the data provided from [25] for the FPA. For the UHT all stages last 330 days [26]. The number of stages for the cultivation phase is different for each technology. The downstream process was assumed to be the same. The land occupied by the FPA is the lowest of the three systems.

Regarding the GWP, air, $\mathrm{CO}_{2}$, nutrient, and water consumption for cleaning and for the process were upscaled linearly. The amount of sodium hypochlorite solution used for sterilizing the PBRs was provided by [45]. The energy consumption of the LED and their weight and material were assumed to be the same as the numbers provided by Subitec GmbH [25]. All the equipment (pumps and heat exchangers) were modeled and the material and power consumption were taken from the providers' manuals. The lifespan of the blower and the pipeline (PE) for gas supply was considered to be 20 years. The equipment parameters are shown in Table 5.

For the FPA, yearly information regarding energy and mass flow were obtained directly from Subitec $\mathrm{GmbH}$ [25]. Therefore, there was no need to design individual equipment as was done with the GWP (Table 5). The LCI of the UHT data were provided by the plant operator

Table 5

Equipment parameters for the large scale Green Wall Panel (GWP) plant. ( $Q_{c o o l}$ is the thermal power to be dissipated (W/ $\left.\mathrm{m}^{2}\right)$ ).

\begin{tabular}{|c|c|}
\hline \multicolumn{2}{|l|}{ Equipment parameters } \\
\hline Thermal power to be dissipated $\left(\mathrm{Q}_{\mathrm{cool}}\right)$ per module $\left(23 \mathrm{~m}^{3}\right)$ & $446 \mathrm{~kW}$ \\
\hline Seawater flowrate per module $\left(\mathrm{M}_{\text {cool }}\right)\left(23 \mathrm{~m}^{3}\right)$ & $38 \mathrm{~m}^{3} / \mathrm{h}$ \\
\hline Seawater flowrate $\left(\mathrm{M}_{\text {cool }}\right)$ total & $154 \mathrm{~m}^{3} / \mathrm{h}$ \\
\hline Sea water pump characteristic & Max flow rate $200 \mathrm{~m}^{3} / \mathrm{h}$ with $8.3 \mathrm{~kW}$ motor \\
\hline Microalgae flowrate (Malgae) (1 module) & $62 \mathrm{~m}^{3} / \mathrm{h}$ \\
\hline 4 algae pumps, one per module $\left(23 \mathrm{~m}^{3}\right)$ & Max flow rate $75 \mathrm{~m}^{3} / \mathrm{h}$ with $11 \mathrm{~kW}$ motor \\
\hline 4 heat exchangers, one per module $\left(23 \mathrm{~m}^{3}\right)$ & Exchange area of $156 \mathrm{~m}^{2}, 244 \mathrm{~kg}$ each, SS \\
\hline Pump from the growing tank to the culture & Polypropylene (PP), $0.37 \mathrm{~kW}, 0-6 \mathrm{~m}^{3} / \mathrm{h}, 9 \mathrm{~kg}$ \\
\hline 1 solution tank & Stinless and steel (SS), $4 \mathrm{~m}^{3}$ \\
\hline Pump from the solution tank to the growing tank & Polypropylene (PP), $0.37 \mathrm{~kW}, 0-6 \mathrm{~m}^{3} / \mathrm{h}, 9 \mathrm{~kg}$ \\
\hline Pump for diluting the solution in the growing tank & Polypropylene (PP), $0.37 \mathrm{~kW}, 0-6 \mathrm{~m}^{3} / \mathrm{h}, 9 \mathrm{~kg}$ \\
\hline Blower & $70 \% \mathrm{SS}, 2.2 \mathrm{~kW}, 106 \mathrm{~m}^{3} / \mathrm{h}, 43 \mathrm{~kg}$ \\
\hline Pipeline for air, sea water, growth medium provision & Polyethylene (PE), $3000 \mathrm{~m}$ \\
\hline Pipeline culture circulation, water recycling & Polyvinylchlorid (PVC), $3000 \mathrm{~m}$ \\
\hline
\end{tabular}


Table 6

Downstream inventory for the three systems (Flat Panel Airlift (FPA), Green Wall panel (GWP) andUnilayer Horizontal Tubular (UHT)).

\begin{tabular}{|c|c|c|c|c|}
\hline & Unit & $\begin{array}{c}\text { Filtration } \\
\text { (Maximal solid output concentration: } 1.5-10 \% \text {, } \\
99 \% \text { recovery) }\end{array}$ & $\begin{array}{l}\text { Centrifugation } \\
\text { (Maximal solid output concentration: } 10-20 \% \text {, } \\
95-99 \% \text { recovery) }\end{array}$ & $\begin{array}{c}\text { Spraydryer } \\
\text { (Maximal solid output concentration: } 90-95 \% \text {, } \\
\text { 99\% recovery) }\end{array}$ \\
\hline GWP & kWh/year & $535.5[46]$ & $45\left(1.3 \mathrm{kWh} \cdot \mathrm{m}^{-3}\right.$ Feed $)$ [37] & $\begin{array}{c}19 \mathrm{E}+03 \\
(1.2 \mathrm{~kg} \text { of evaporated water) [37] }\end{array}$ \\
\hline UHT & $\mathrm{kWh} /$ year & $1180[26]$ & $34.5[26]$ & $\begin{array}{c}21 \mathrm{E}+03 \\
(1.2 \mathrm{~kg} \text { of evaporated water) [37] }\end{array}$ \\
\hline FPA & $\mathrm{kWh} /$ year & $640[46]$ & $219\left(1.3 \mathrm{kWh} \cdot \mathrm{m}^{-3}\right.$ Feed $)$ [37] & $\begin{array}{c}\text { 92E }+03 \\
\text { (1.2 kg of evaporated water) [37] }\end{array}$ \\
\hline
\end{tabular}

A4F GmbH [26]. Regarding the downstream and extraction process, detailed information can be found in Table 6 .

In general, the energy consumption of equipment was calculated from its power requirement multiplied by the operation time. Quantity of building materials was calculated by multiplying the volume and the density. A lifespan of 5 years was assumed for the GWP, 10 years for the FPA and UHT-PBRs, and 20 years for the other process equipment. Regarding the background system, information from the Ecoinvent database 3.3 were used [47]. These data include the material and energy flows for the supply of nutrients, materials, and electricity, and for waste disposal. The inventory was then normalized to $1 \mathrm{~kg}$ of $\mathrm{H}$. pluvialis and $1 \mathrm{~kg}$ of astaxanthin respectively.

\subsubsection{Impact assessment methodology}

The impact assessment methodology used in this work is ReCiPe (midpoint $(\mathrm{H})$ ) 2014, because it was already proved to be representative on a global scale and therefore suitable for intercountry comparisons [11]. The impact assessment categories were selected according to that used in previous LCA studies [10]. The inventory was implemented in OpenLCA 1.6

\subsubsection{System expansion}

The amount of astaxanthin contained in the biomass is very low (2.1-10\%), and the amount of residual biomass after astaxanthin extraction is high and contains protein, lipids and carbohydrates that can be used for further processes. From the economic and environmental perspectives, there is evidence that the residual algae biomass should be considered as by-products rather than as waste. Thus, there is the need to credit the by-product by giving value to the residual biomass and considering it as a multifunctional process. From the LCA perspective, there are two different methodological approaches to handle multifunctional processes: system expansion and the allocation method. System expansion is applied in order to ensure that all the products of the process offer the same functionalities [48]. To achieve this goal, the system must be expanded in such a way that the other functionalities are included. This requires the identification of the most probable

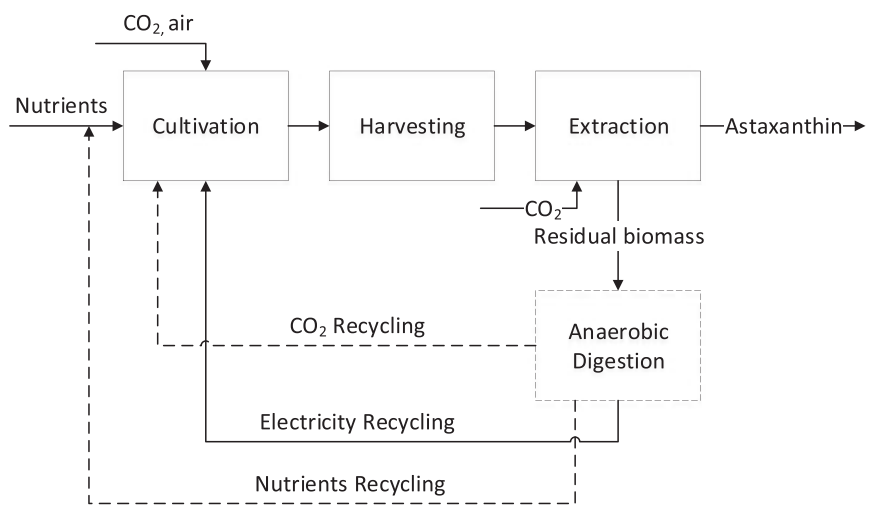

Fig. 4. System expansion of the extraction process, including the Anaerobic Digestion process.

\section{Table 7}

LCA Scenarios for the valorization of the residual algae biomass form astaxanthin production for the three systems (Flat Panel Airlift (FPA), Green Wall panel (GWP) andUnilayer Horizontal Tubular (UHT)).

\begin{tabular}{lcccc}
\hline \multirow{2}{*}{ Scenarios } & \multicolumn{3}{c}{ Astaxanthin $\%$} & Methane yield $\mathrm{LCH}_{4} / \mathrm{gVS}$ \\
\cline { 2 - 4 } & GWP & FPA & UHT & \\
\hline SC1 & 2.6 & 4.8 & 2.12 & 0.026 \\
SC2 & 2.6 & 4.8 & 2.12 & 0.6 \\
SC3 & & 10 & & 0.026 \\
SC4 & & 10 & & 0.6 \\
\hline
\end{tabular}

alternative way to provide the second functionality, i.e. a process that produces this functionality. In this way the environmental impact (EI) associated with this process can be detected from the main process, saving money and reducing the global EI. The approach of system expansion is mathematically equivalent to crediting for avoided production. This method is the one preferred by the ISO 14040 and 14044 standards. When the allocation method is applied, the flows are partitioned to the different products according to an allocation key that can be based on the weight or economic value (price). Since it is not always possible to divide the flows, this approach is limited in its application. In the framework of this study, we selected the system expansion methodology. There are mainly two processes that can be used to suggested the use of residual algae biomass as feedstock for anaerobic digestion. In this study, we analyse both alternatives for residual biomass use, anaerobic digestion and animal feed.

\subsubsection{Anaerobic digestion}

In order to include anaerobic digestion, a biogas plant near to the algae cultivation plant was assumed (the digester was not included in the boundaries). Generally in the anaerobic digestion (AD) process, there are three main products: methane $\left(\mathrm{CH}_{4}\right)$, carbon dioxide $\left(\mathrm{CO}_{2}\right)$ and nutrients. In our study, only two products were assumed, $\mathrm{CH}_{4}$ and $\mathrm{CO}_{2}$, and that only electricity produced by the biogas was recycled to the cultivation stage. Based on the work of Collet et al. [14] we assumed that the biogas comprises a share of $70 \% \mathrm{CH}_{4}$ and $30 \% \mathrm{CO}_{2}$. In order to credit the system, we considered an average amount of methane that can be produced from the digestion of the biomass $\left(0.024-0.6 \mathrm{LCH}_{4} /\right.$ gVS (VS = volatile solids)). Based on the fact that each $\mathrm{m}^{3}$ of methane can produce $2 \mathrm{kWh}$ [49] of electric power, the amount of electricity

Table 8

Electricity production from residual algae biomass digestion in four scenarios (SC1, SC2, SC3, SC4).

\begin{tabular}{lccc}
\hline Scenarios & \multicolumn{3}{c}{ Electric power produced $(\mathrm{kWh})$} \\
\cline { 2 - 4 } & GWP & FPA & UHT \\
\hline SC1 & 1.99 & 1.05 & 2.46 \\
SC2 & 49.81 & 26.37 & 61.39 \\
SC3 & & 0.48 & \\
SC4 & & 11.94 & \\
\hline
\end{tabular}




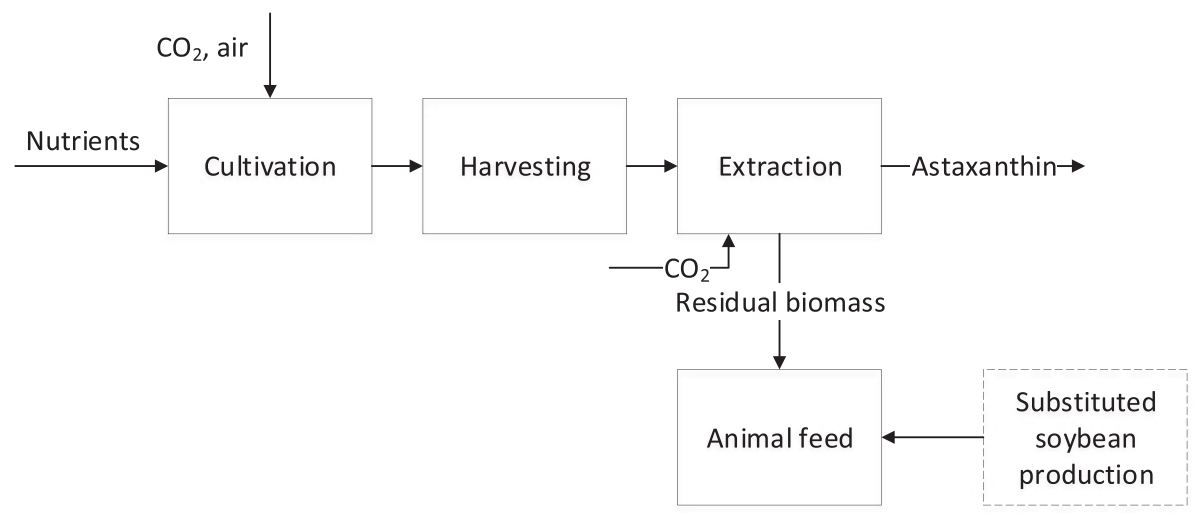

Fig. 5. System expansion of the extraction process including feed production.

produced by the digestion of microalgae was estimated (Fig. 4).

Since the amount of astaxanthin in $H$. pluvialis is $2.12,2.6$ and $4.8 \%$ for the three technologies UHT, GWP and FPA respectively, a theoretical value of $10 \%$ is achievable, and the yield of $\mathrm{CH}_{4}$ from the biomass digestion can also vary $\left(0.024-0.6 \mathrm{LCH}_{4} / \mathrm{gVS}\right.$ (VS = volatile solids)) [50], four scenarios were elaborated. Table 6 depicts the scenarios elaborated and assessed, combining different shares of astaxanthin in the biomass (2.6, 4.8 and 10\%) and two different yields of methane (0.024, $0.6 \mathrm{LCH}_{4} / \mathrm{gVS}$ ). Applying this scenario approach helps to identify the influence of main driving factors (astaxanthin and methane yield) on the environmental impact (Table 7).The LCA calculation was performed for all systems.

Table 8 shows the electricity produced when the different scenarios were considered for the production of $1 \mathrm{~kg}$ of astaxanthin.

The amount of methane obtained from the digestion of microalgae is low, indeed the $100 \mathrm{LCH}_{4} / \mathrm{gVS}$ can be achieved only when seaweeds are used [51]. From the results shown in Table 8, it can be concluded that lower astaxanthin content comes along with a higher amount of residual biomass and electricity production. At this point, it is necessary to understand which scenario is environmentally more convenient.

\subsubsection{Feed production}

In the case of feed production, from the LCA perspective, system expansion was considered in order to include a process whose environmental impact is avoided when this expansion is performed. Feed grain, and in particular soybean, are the most important source of animal feed worldwide. For this reason, the substituted soybean production was included in the system boundary, as shown in Fig. 5.

\section{Results and discussion}

This study analysed different final products and scenarios to consider the residual algae biomass after astaxanthin extraction. The first case assessed the potential environmental impact of $H$. pluvialis. Since the red powder obtained after the spraydryer can also be sold as a final product, without extracting astaxanthin, the potential environmental impact (EI) of the production of $1 \mathrm{~kg}$ of $\mathrm{H}$. pluvialis in the three PBRs was estimated. Then, the potential EI of the production of $1 \mathrm{~kg}$ of astaxanthin was evaluated.

\subsection{Life cycle assessment (LCA) for H. pluvialis production}

The potential environmental impact for the production of $1 \mathrm{~kg}$ of $H$. pluvialis was estimated for the three PBR systems. The results of the analysis are described in Table 9 and displayed in Figs. 6 and 7. Table 9 illustrates the characterization results for biomass production. For FPA, two scenarios were considered, using the French and German energy mix; for UHT and GWP only the Portuguese and French energy mixes were considered, respectively. Since the UHT and GWP technologies do not include artificial light, a change in the location would mean a change in the productivity. The FPA is located inside a building. Therefore, the location does not affect productivity. The results are

Table 9

LCA results for the three systems (Flat Panel Airlift (FPA), Green Wall panel (GWP) and Unilayer Horizontal Tubular (UHT)), using the French (FR), German (DE), Portuguese (PT) energy mix.

\begin{tabular}{|c|c|c|c|c|c|}
\hline Name & Unit & FPA (DE) mix & FPA (FR) mix & GWP (FR) mix & UHT (PT) mix \\
\hline Agricultural land occupation (ALO) & $\mathrm{m}^{2 * \mathrm{a}}$ & 22.45 & 5.81 & 7.08 & 3.82 \\
\hline Climate change (CC) & $\mathrm{kg} \mathrm{CO} \mathrm{CO}_{2}$ eq & 265.21 & 80.62 & 91.37 & 20.93 \\
\hline Fossil depletion (FD) & $\mathrm{kg}$ oil eq & 64.48 & 19.39 & 25.84 & 5.16 \\
\hline Freshwater ecotoxicity (FET) & $\mathrm{kg} 1,4-\mathrm{DB}$ eq & 5.92 & 1.99 & 2.36 & 0.26 \\
\hline Freshwater eutrophication (FE) & $\mathrm{kg} \mathrm{P}$ eq & 0.30 & 0.04 & 0.05 & 0.01 \\
\hline Human toxicity (HT) & $\mathrm{kg} 1,4-\mathrm{DB}$ eq & 204.19 & 54.40 & 69.67 & 6.35 \\
\hline Ionising radiation (IR) & kg U235 eq & 46.54 & 189.57 & 193.59 & 2.17 \\
\hline Marine ecotoxicity (MET) & kg 1,4-DB eq & 5.56 & 1.83 & 2.17 & 0.25 \\
\hline Marine eutrophication (ME) & $\mathrm{kg} \mathrm{N}$ eq & 0.08 & 0.03 & 0.03 & 0.00 \\
\hline Metal depletion (MD) & $\mathrm{kg} \mathrm{Fe} \mathrm{eq}$ & 16.05 & 16.27 & 20.93 & 1.43 \\
\hline Natural land transformation (NLT) & $\mathrm{m}^{2}$ & 0.02 & 0.01 & 0.01 & 0.00 \\
\hline Ozone depletion (OD) & $\mathrm{kg} \mathrm{CFC-11} \mathrm{eq}$ & 0.00 & 0.00 & 0.00 & 0.00 \\
\hline Particulate matter formation (PMT) & kg PM10 eq & 0.23 & 0.18 & 0.22 & 0.04 \\
\hline Photochemical oxidant formation (POF) & kg NMVOC & 0.35 & 0.21 & 0.26 & 0.06 \\
\hline Terrestrial acidification (TA) & $\mathrm{kg} \mathrm{SO}_{2} \mathrm{eq}$ & 0.52 & 0.35 & 0.44 & 0.12 \\
\hline Terrestrial ecotoxicity (TET) & kg 1,4-DB eq & 0.01 & 0.01 & 0.01 & 0.00 \\
\hline Urban land occupation (ULO) & $\mathrm{m}^{2 * \mathrm{a}}$ & 1.27 & 0.63 & 0.81 & 0.29 \\
\hline Water depletion (WD) & $\mathrm{m}^{3}$ & 938.69 & 1577.02 & 1666.90 & 148.54 \\
\hline
\end{tabular}



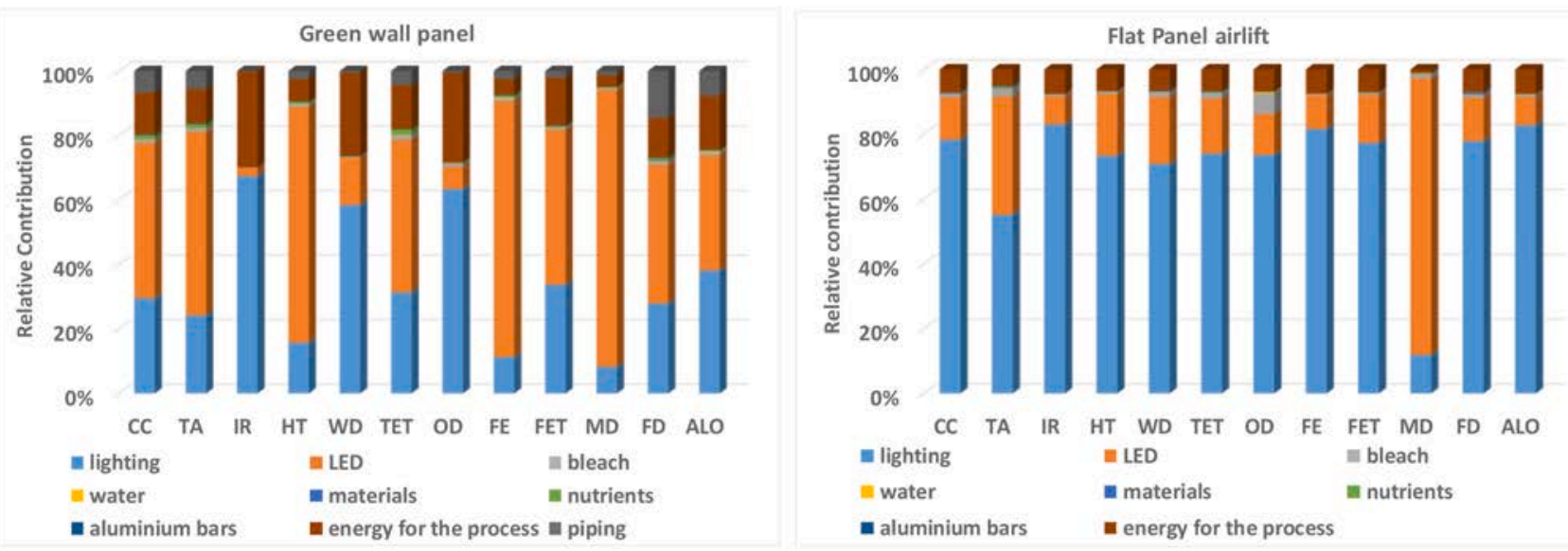

Fig. 6. Potential environmental impact for the production of $1 \mathrm{~kg}$ of $\mathrm{H}$. pluvialis using Green Wall Panel a) and Flat Panel Airlift b) as photobioreactors. (Climate Change (CC), Terrestrial acidification (TA), Ionising radiation (IR), Human toxicity (HT), Water depletion (WD), Terrestrial ecotoxicity (TET), Ozone depletion (OD), Freshwater eutrophication (FE), Freshwater ecotoxicity (FET), Metal depletion (MD), Fossil depletion (FD), Agricultural land occupation (ALO)).

presented in Figs. 6 and 7. Fig. 7 shows how the results of the FPA change, by changing the energy mix. The figures show the relative contribution of each process involved in the production chain i.e. lighting, LED production, bleach, water, material (includes materials equipment), nutrients, aluminum bars, energy for the process (electric energy used by all the devices), and the piping. For all systems, the second stage or red phase is the main hotspot for all the impact categories, with a contribution of $80-85 \%$. The cultivation stage usually gives the highest environmental impact [10,52]. Fig. 6 illustrates the potential environmental impact of the large pilot-scale GWP and FPA. Regarding the GWP, the main hotspot is due to the LED production system (mainly diode production), and therefore to the electricity needed for their production.

For Metal Depletion (MD), Freshwater Eutrophication (FE), and Human Toxicity (HT), the main contribution is due to the material used for the diode production, including tin and molybdenum, and also energy consumption for LED production. Lighting is the second hotspot of the system, due to electricity consumption.

The energy consumption for the process, including the energy consumption of the pumps and the blower, also has an impact. This could be reduced by using more efficient equipment. The other materials, in general, do not have a big effect on all the impact categories.

The lighting and energy used for the process affects mainly Ionising Radiation (IR), Water Depletion (WD), and Ozone Depletion (OD). IR and OD are mainly affected by the electricity production from the nuclear power plant (emission of Radon 222 and Carbon 14 in one case, and of light hydrocarbon in the other). The WD from electricity production is due to the methodological assumption that the water used in the hydropower plant is "used", although it is not consumed, but only used for driving the water turbine.

The LED production affects Climate Change (CC), Terrestrial Acidification (TA), Human Toxicity (HT), Freshwater Eutrophication (FE), and Metal Depletion (MD). The electricity used to produce LEDs in a global market affects the CC. TA and FE are affected by the diode production (emission of sulfur dioxide and nitrogen oxides to air, and phosphate in water). HT is affected by the molybdenum and copper used for diode production. MD is affected by the usage of tin, molybdenum, copper and other metals used for LED production.

Regarding the FPA, when the German energy mix is used, lighting is the main hotspot, but the EI is reduced significantly if the electricity mix changes. LED production is also a hotspot, and since the number of LEDs used is high, the potential environmental impact is also high.

Fig. 7a shows the potential environmental impact for the production of $1 \mathrm{~kg}$ of $H$. pluvialis using the UHT as a cultivation system. Even though the productivity is lower than those of the other PBR systems, the potential EI is lower for all the impact categories. Since the time considered as the cultivation period is different from the other two systems (330 vs 225), in order to be sure that the results were
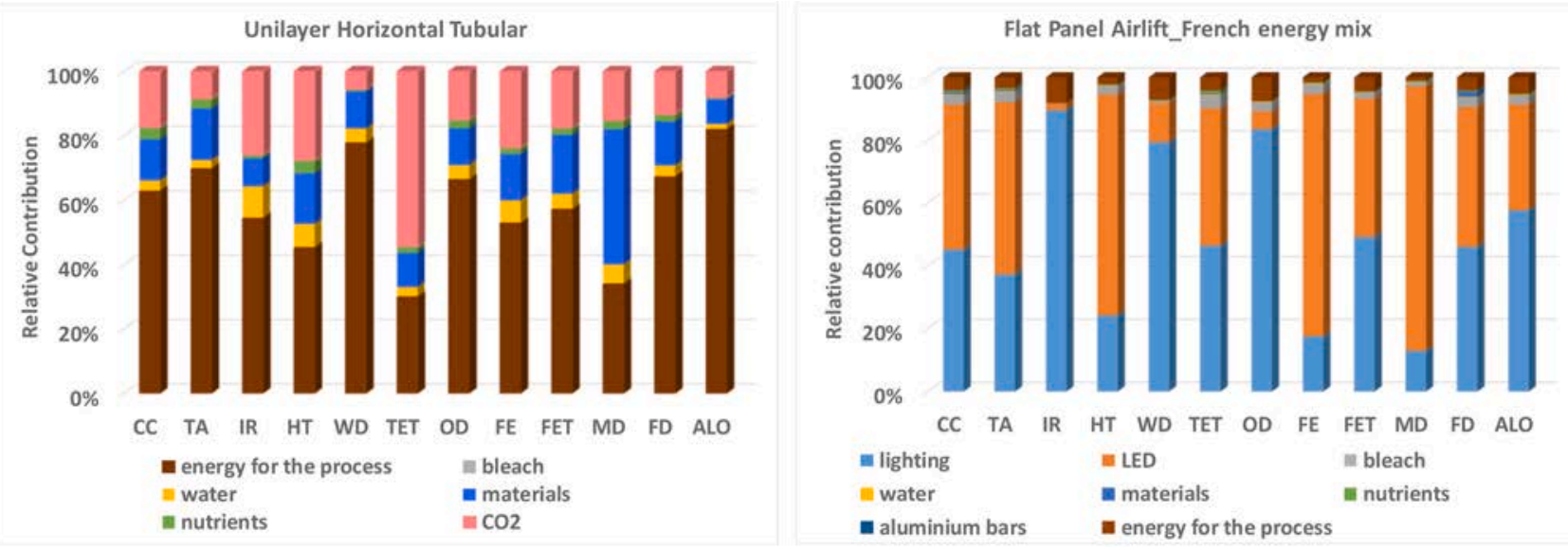

Fig. 7. Potential environmental impact for the production of $1 \mathrm{~kg}$ of $H$. pluvialis using the the Unilayer Horizontal Tubulat (UHT) a) and the Flat Panel Airlift (FPA) with French energy mix b). (Climate change (CC), Terrestrial acidification (TA), Ionising radiation (IR), Human toxicity (HT), Water depletion (WD), Terrestrial ecotoxicity (TET), Ozone depletion (OD), Freshwater eutrophication (FE), Freshwater ecotoxicity (FET), Metal depletion (MD), Fossil depletion (FD), Agricultural land occupation (ALO)). 
Table 10

Composition of the electricity mix in Germany, France and Portugal (Data from Ecoinvent 3.3. 2012)

\begin{tabular}{lccc}
\hline & $\begin{array}{c}\text { German energy mix } \\
2009\end{array}$ & $\begin{array}{c}\text { French energy mix } \\
2009\end{array}$ & $\begin{array}{c}\text { Portuguese energy mix } \\
2009\end{array}$ \\
\hline Fossil fuel & 59.5 & 9.1 & 89.2 \\
Nuclear & 23.8 & 76.4 & - \\
Renewable & 15.2 & 13.9 & 4.5 \\
Waste & 1.5 & 0.6 & 0.3 \\
\hline
\end{tabular}

independent from this variable, the same analysis was performed taking into account a cultivation period of 225 days and the results were practically the same (see Supplementary Material).

The main hotspots are energy consumption for the process, $\mathrm{CO}_{2}$ production, and material production. The energy consumption of the process includes the electricity for mixing the culture $(5.6 \mathrm{E}+4 \mathrm{kWh}$ / year, highest contribution) and the nutrients, the filtration of the nutrients, and the downstream process. Regarding the electricity demand for mixing, a recent study [53] analysed the impact of several mixing regimes with lower energy inputs on the well-mixed condition. The authors demonstrated that differences in the mixing energy concepts do not have a significant impact on the particles' motion. Therefore, it is possible to decrease the energy consumption for mixing (by choosing a pump with lower energy consumption) without affecting the mixing condition.

The $\mathrm{CO}_{2}$ is supplied due to the pressure difference between the cylinder and the reactor. Therefore, the EI associated with the production of liquid $\mathrm{CO}_{2}$ was considered. Moreover, in this case pure $\mathrm{CO}_{2}$ is used instead of air enriched with $\mathrm{CO}_{2}$. The energy consumed for mixing the culture is the main contribution for almost all impact categories. For MD and Urban Land Occupation (ULO) the main contribution is due to the market of steel for manifold production, and to the market of the glass tube for the PBR production.

Fig. 7b shows that Climate Change (CC) of the FPA can be reduced by $2 / 3$ from 265 to $84 \mathrm{~kg} \mathrm{CO}_{2}$ eq./ $/ \mathrm{kg}$ algae biomass when the French energy mix is used due to the higher share of nuclear power, even though the IR increases three times (from 47 to $190 \mathrm{~kg}$ of U235 eq/ kg algae biomass). LED production is the main hotspot when the French energy mix is used, affecting the environmental categories CC, MD, FET and HT due to the material used for LED production, including tin and molybdenum (Fig. 7). Other hotspots are lighting and energy for the process (energy consumption of pumps, blower, etc.) that affect IR and OD due to the emissions related to the use of the nuclear plant as an energy source. WD is high due to the water turbined in the hydropower plant (higher share in France). It is important to note that the three

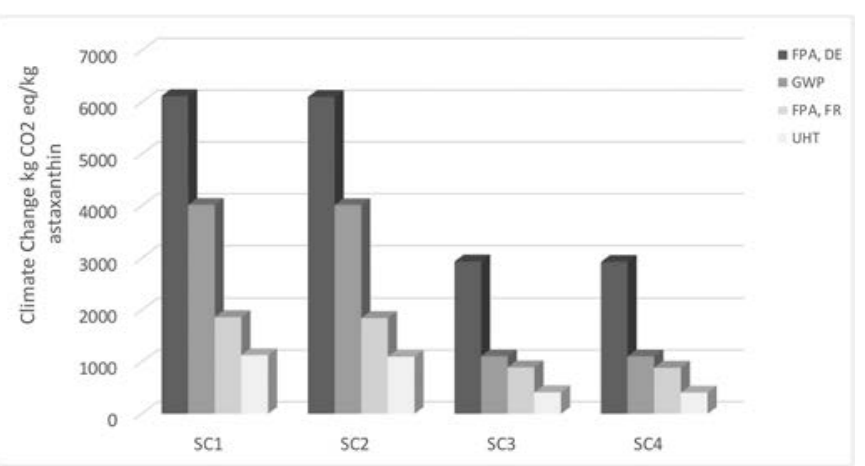

Fig. 9. Variation of the Climate Change with the astaxanthin $\%$ and $\mathrm{CH}_{4}$ yield (identified with the four scenarios SC1, SC2, SC3, SC4) for the three systems (Flat Panel Airlift (FPA), Green Wall panel (GWP) and Unilayer Horizontal Tubular (UHT)), using the French (FR), German (DE), Portuguese (PT) energy mix.

systems are located in different European regions, and three different energy mixes were taken from Ecoinvent 3.3. Table 10 shows the main differences among the French, German and Portuguese energy mixes.

The electricity mix in Germany has changed since 2012, so it can be expected that the LCA results would be different if the current electricity mix was considered. However, modeling the current mix would have gone beyond the scope of this work. Fig. 8 shows that the potential environmental impact of the FPA located in Germany is higher than the one in France.

The same happens if we compare it with the GWP. Only two categories are different. The IR is different due to the emissions related to nuclear power, which is the main source of energy. The MD has a value of $16 \mathrm{~kg} \mathrm{Fe}$ eq for the FPA, and $20 \mathrm{~kg} \mathrm{Fe}$ eq for the GWP. This is due to the material used for LED production (mainly tin) and does not change with energy mix. The different value is related to the configuration of the two plants. In fact, the green phase of the GWP has a higher value of LED per $\mathrm{kg}$ of biomass produced than the FPA due to its higher productivity. For this reason, when the French energy mix is considered, the potential environmental impact of the GWP is slightly higher than for the FPA. For all the impact categories it is clear that the UHT is characterized by the lowest EI. This effect is caused by the use of natural light rather than the construction of the PBR technology itself.

\subsection{Life cycle assessment (LCA) for the astaxanthin production}

The potential environmental impact of the production of $1 \mathrm{~kg}$ of

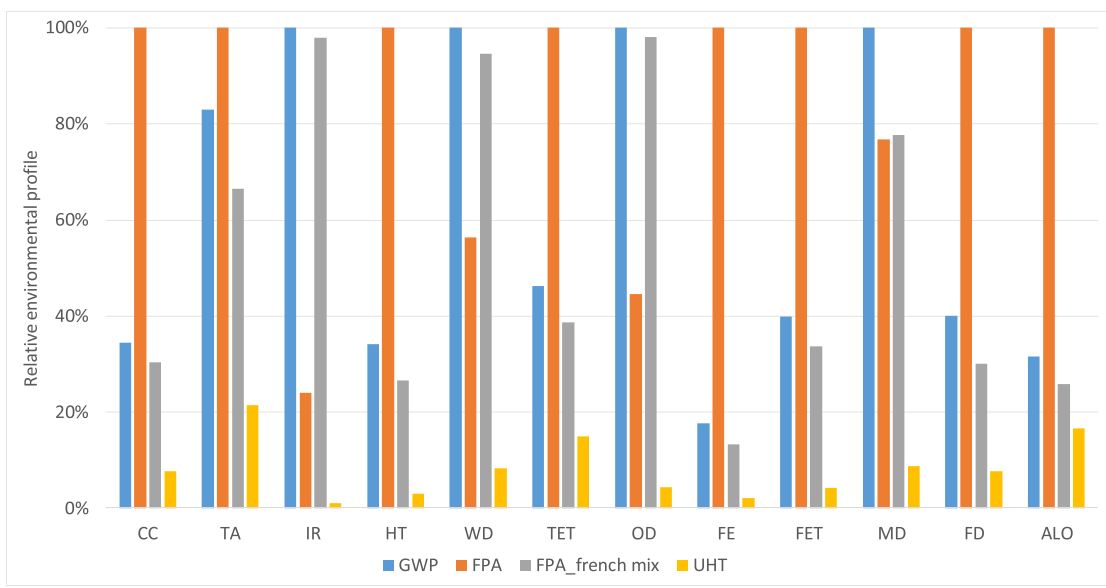

Fig. 8. Relative environmental profile of the three photobioreactor systems(Flat Panel Airlift (FPA), Green Wall panel (GWP) and Unilayer Horizontal Tubular (UHT)). 
Table 11

Comparison of the two LCA system expansion methodologies: residual biomass use for biogas (for the different scenarios SC1, SC2, SC3, SC4) or feed production, for the three systems (Flat Panel Airlift (FPA), Green Wall panel (GWP) and Unilayer Horizontal Tubular (UHT)) using the French (FR) and German (DE), energy mix. ((Terrestrial ecotoxicity (TET), Natural land transformation (NLT), Fossil depletion (FD), Agricultural land occupation (ALO), Climate change (CC)).

\begin{tabular}{|c|c|c|c|c|c|}
\hline & TET(kg 1,4-DB eq) & $\operatorname{NLT}\left(\mathrm{m}^{2}\right)$ & FD (kg oil eq) & $\operatorname{ALO}\left(m^{2 * a}\right)$ & $\mathrm{CC}\left(\mathrm{kg} \mathrm{CO} \mathrm{C}_{2}\right.$ eq $)$ \\
\hline SC1, GWP & 0.27 & 0.60 & 1188.40 & 307.15 & 4017 \\
\hline SC4, GWP & 0.07 & 0.16 & 366.15 & 81.75 & 1108 \\
\hline Feed production, $2.6 \%$ GWP & -2.29 & -0.34 & 1051.44 & 181.73 & 3648 \\
\hline Feed production, $10 \%$, GWP & -0.55 & -0.07 & 342.60 & 52.70 & 1035 \\
\hline SC1, UHT & 0.06 & 0.18 & 358.82 & 213.48 & 1131.64 \\
\hline SC4, UHT & 0.06 & 0.18 & 350.82 & 206.21 & 1101.40 \\
\hline Feed production, $2.12 \%$ UHT & -3.12 & -0.97 & 354.97 & 80.90 & 938.39 \\
\hline Feed production, $10 \%$, UHT & -0.60 & -0.17 & 173.32 & 41.95 & 377.69 \\
\hline SC1, FPA & 0.32 & 0.46 & 1487.51 & 517.93 & 6119 \\
\hline SC1, FPA FR mix & 0.12 & 0.27 & 448.62 & 134.24 & 1865 \\
\hline SC4, FPA FR mix & 0.06 & 0.13 & 213.66 & 63.82 & 888 \\
\hline Feed production, $4.8 \%$, FPA DE mix & -1.05 & -0.04 & 1485.89 & 460.90 & 6036 \\
\hline Feed production, $4.8 \%$, FPA FR mix & -1.25 & -0.23 & 446.99 & 77.21 & 1783 \\
\hline Feed production, $10 \%$, FPA DE mix & -0.47 & -0.01 & 714.08 & 222.99 & 2902 \\
\hline Feed production, $10 \%$, FPA FR mix & -0.56 & -0.10 & 214.73 & 38.57 & 857 \\
\hline
\end{tabular}

astaxanthin was also evaluated. The analysis was performed for the three PBR systems.

\subsubsection{System expansion with anaerobic digestion $(A D)$}

Since the amount of astaxanthin contained in $H$. pluvialis is low, the environmental impact related to the production of pure astaxanthin is high, even after crediting a system $(400-4000 \mathrm{~kg} \mathrm{CO}$ eq. $/ \mathrm{kg}$ of astaxanthin produced). Taking into account that the electricity was selected as avoided product and affects mainly the CC, results regarding this impact category are displayed in Fig. 9. The graph shows the variation of CC for the scenarios described in Table 7. The best results can be achieved with the highest astaxanthin content. Indeed, if the $\mathrm{LCH}_{4} / \mathrm{gVS}$ is constant (SC1-SC3 and SC2-SC4), an increase in astaxanthin content results in a reduction in EI. If the astaxanthin content is constant (SC1SC2 and SC3-SC4), the results do not change. Therefore, the best results could be achieved if the astaxanthin content increases. In particular, since in the UHT configuration no artificial light is used, it shows the best results for all the scenarios.

\subsubsection{System expansion with feed production}

The LCA system expansion approach was also performed considering the application of the residual algae biomass after astaxanthin extraction for feed production. The results of the LCA show that with the integration of the substituted soybean production, there is a negative impact on two impact categories: terrestrial ecotoxicity (TET) and natural land transformation (NLT). A comparison between the LCA results for the production of $1 \mathrm{~kg}$ of astaxanthin in the case of feed production (with $2.12 / 2.6 / 4.8$ and $10 \%$ of astaxanthin content), and SC1 and SC4 has been performed. The best results (Table 11) for these categories are obtained when the biomass contains $10 \%$ of astaxanthin for the three systems and for both system expansion methodologies. Therefore, the higher the astaxanthin content, the lower the potential environmental impacts.

Some categories even show a negative impact due to the avoided soybean production. In particular, NLT is negative because there is a negative flow related to the transformation of forests. The TET shows a negative impact due to avoided emissions related to the production of soybeans (e.g. cypermethrin).

\section{Conclusion}

Life cycle assessment (LCA) is a powerful tool to identify and analyse the hotspots of a production process, and provides valuable insights and recommendations for engineers during process design, and also decision-makers in industry, politics and sciences. The comparative LCA is mainly based on original data from pilot plants, which were checked and validated by engineers. Electricity production has been identified as the overall hotspot for the three different photobioreactor technologies (FPA, GWP and UHT) located in different climatic regions (Stuttgart, Germany; Lisbon, Portugal, and Montpellier, France) under different conditions (inside with double-sided lighting (FPA), outside with one-sided lighting (GWP), and outside without lighting (UHT$\mathrm{PBR})$ ). The diode production process was another main hotspot for the GWP and the second environmental burden for the FPA.

The present study gives the potential to analyse how the location and the means to produce electricity affect the potential environmental impacts. As an example, it was shown that in the FPA, climate change impact decreases by $2 / 3$ when the energy mix changes away from coal and oil to nuclear power, since this is $\mathrm{CO}_{2}$-neutral technology to produce electricity. If electricity was produced from renewable resources, the environmental impact would decrease even further, including in other environmental impact categories. Moreover, since two functional units were selected, this paper gives the potential to analyse how much the potential EI increases when astaxanthin is considered. Indeed, even crediting the system, the environmental burdens are allocated to astaxanthin, which constitutes a small amount of the biomass. This is the reason why productivity is an important parameter in the algae sector, and the production of added value compounds seems to be the only sector where the microalgae can be used with a high return of investment. Moreover, using the system expansion methodology it was possible to highlight how useful it could be from the environmental point of view to produce animal feed from the residual biomass. This will affect positively the soybean production sector, with a negative contribution to several impact categories.

Despite some differences between the three process stages, for the first time in this paper, three different photobioreactor systems are compared at large pilot scale. The results show that more research and development is needed in order to design and operate a technology that is more environmentally friendly than the existing ones. Just waiting for a successful energy transition to supply renewable energy is not a solution for sustainable algae processes and product development.

\section{CRediT authorship contribution statement}

Cristina Onorato: Conceptualization, Methodology, Validation, Writing - original draft, Writing - review \& editing. Christine Rösch: Supervision, Funding acquisition, Writing - review \& editing. 


\section{Declaration of competing interest}

The authors declare that they have no known competing financial interests or personal relationships that could have appeared to influence the work reported in this paper.

\section{Acknowledgments}

The present work has been funded by the project ABACUS that receives funding from the Bio-Based Industries Joint Undertaking under the European Union's Horizon 2020 research and innovation program (Grant Agreement $\mathrm{N}^{\circ}$ 745668). We gratefully acknowledge input and assistance from Peter Bergman of the Subitec $\mathrm{GmbH}$ and Celina Parreira, Andre Silva, Luis Costa, L. Tiago Guerra from A4F.

\section{Author contribution}

Cristina Onorato conceptualized the structure of the manuscript, conducted the acquisition of data and the analysis, performed the analysis and wrote the manuscript. Christine Rösch was responsible for the supervision of the work, review of the manuscript and funding acquisition.

\section{Statement of informed consent, human or animal rights}

No conflicts, informed consent, human or animal right applicable.

\section{References}

[1] T.L. da Silva, A. Reis, Scale-up problems for the large scale production of algae, in D. Das (Ed.), Algal Biorefinery: An Integrated Approach, Springer International Publishing, Cham, 2015, pp. 125-149.

[2] P. Collet, A. Hélias, L. Lardon, J.-P. Steyer, O. Bernard, Recommendations for life cycle assessment of algal fuels, Appl. Energy 154 (2015) 1089-1102.

[3] W. Barclay, K. Apt, Strategies for bioprospecting microalgae for potential commercial applications, Handbook of Microalgal Culture, 2013, pp. 69-79.

[4] K.S. Khoo, S.Y. Lee, C.W. Ooi, X. Fu, X. Miao, T.C. Ling, et al., Recent advances in biorefinery of astaxanthin from Haematococcus pluvialis, Bioresour. Technol. 288 (Sep 2019) 121606.

[5] D. Han, Y. Li, Q. Hu, Biology and commercial aspects of Haematococcus pluvialis, Handbook of Microalgal Culture, 2013, pp. 388-405.

[6] R.K. Saini, Y.-S. Keum, Carotenoid extraction methods: a review of recent developments, Food Chem. 240 (2018) 90-103.

[7] M.M.R. Shah, Y. Liang, J.J. Cheng, M. Daroch, Astaxanthin-producing green microalga Haematococcus pluvialis: from single cell to high value commercial products, Front. Plant Sci. 7 (2016) (2016-April-28).

[8] K.D. Nguyen, Astaxanthin: A Comparative Case of Synthetic Vs. Natural Production, (2013).

[9] N.J. Bai, B.B. Nair, V. Shashirekha, Conditions promoting astaxanthin production in Haematococcus, Haematococcaceae, Chlorophyceae, with special reference to $\mathrm{H}$. pluvialis, Phycol. Soc. India 2 (2017) 25-38.

[10] P. Pérez-López, S. González-García, C. Jeffryes, S.N. Agathos, E. McHugh, D. Walsh, et al., Life cycle assessment of the production of the red antioxidant carotenoid astaxanthin by microalgae: from lab to pilot scale, J. Clean. Prod. 64 (2014) 332-344 (2014/02/01/)

[11] S. Schade, T. Meier, A comparative analysis of the environmental impacts of cultivating microalgae in different production systems and climatic zones: a systematic review and meta-analysis, Algal Res. 40 (2019) 101485.

[12] G.C. Zittelli, N. Biondi, L. Rodolfi, M.R. Tredici, Photobioreactors for mass production of microalgae, Handbook of Microalgal Culture, 2013, pp. 225-266.

[13] P. Perez-Lopez, J.H. de Vree, G. Feijoo, R. Bosma, M.J. Barbosa, M.T. Moreira, et al., Comparative life cycle assessment of real pilot reactors for microalgae cultivation in different seasons, Appl. Energy 205 (2017) 1151-1164.

[14] P. Collet, A. Hélias, L. Lardon, M. Ras, R.-A. Goy, J.-P. Steyer, Life-cycle assessment of microalgae culture coupled to biogas production, Bioresour. Technol. 102 (2011) 207-214 (2011/01/01/)

[15] O. Jorquera, A. Kiperstok, E.A. Sales, M. Embiruçu, M.L. Ghirardi, Comparative energy life-cycle analyses of microalgal biomass production in open ponds and photobioreactors, Bioresour. Technol. 101 (2010) 1406-1413 (2010/02/01/).
[16] L. Lardon, A. Helias, B. Sialve, J.-P. Steyer, O. Bernard, Life-cycle Assessment of Biodiesel Production From Microalgae, ACS Publications, 2009.

[17] L. Brennan, P. Owende, Biofuels from microalgae-a review of technologies for production, processing, and extractions of biofuels and co-products, Renew. Sust. Energ. Rev. 14 (2010) 557-577 (2010/02/01/).

[18] T.E. McKone, W.W. Nazaroff, P. Berck, M. Auffhammer, T. Lipman, M.S. Torn, et al., Grand challenges for life-cycle assessment of biofuels, Environ. Sci. Technol. 45 (2011) 1751-1756 (2011/03/01)

[19] H. Passell, H. Dhaliwal, M. Reno, B. Wu, A. Ben Amotz, E. Ivry, et al., Algae biodiesel life cycle assessment using current commercial data, J. Environ. Manag. 129 (2013) 103-111 (11/15/2013).

[20] R. Slade, A. Bauen, Micro-algae cultivation for biofuels: cost, energy balance, environmental impacts and future prospects, Biomass Bioenergy 53 (2013) 29-38 $(2013 / 06 / 01 /)$

[21] C.M. Beal, L.N. Gerber, D.L. Sills, M.E. Huntley, S.C. Machesky, M.J. Walsh, et al., Algal biofuel production for fuels and feed in a 100-ha facility: a comprehensive techno-economic analysis and life cycle assessment, Algal Res. 10 (2015) 266-279 $(2015 / 07 / 01 /)$

[22] L.B. Brentner, M.J. Eckelman, J.B. Zimmerman, Combinatorial life cycle assessment to inform process design of industrial production of algal biodiesel, Environ. Sci. Technol. 45 (Aug 15, 2011) 7060-7067.

[23] M. Collotta, L. Busi, P. Champagne, F. Romagnoli, G. Tomasoni, W. Mabee, et al., Comparative LCA of three alternative technologies for lipid extraction in biodiesel from microalgae production, Energy Procedia 113 (2017) 244-250.

[24] K. Kyriakopoulou, S. Papadaki, M. Krokida, Life cycle analysis of $\beta$-carotene extraction techniques, J. Food Eng. 167 (2015) 51-58.

[25] Subitec GmbH, (Personal Communication).

[26] A4F GmbH, (Personal Communication).

[27] Microphyt GmbH, (Personal Communication)

[28] M.R. Tredici, L. Rodolfi, N. Biondi, N. Bassi, G. Sampietro, Techno-economic analysis of microalgal biomass production in a 1-ha Green Wall Panel (GWP ${ }^{\oplus}$ ) plant, Algal Res. 19 (2016) 253-263.

[29] www.maproint.com.

[30] M. Tredici, N. Bassi, M. Prussi, N. Biondi, L. Rodolfi, G.C. Zittelli, et al., Energy balance of algal biomass production in a 1-ha "Green Wall Panel" plant: how to produce algal biomass in a closed reactor achieving a high net energy ratio, Appl. Energy 154 (2015) 1103-1111.

[31] C. Quiroz Arita, O. Yilmaz, S. Barlak, K.B. Catton, J.C. Quinn, T.H. Bradley, A geographical assessment of vegetation carbon stocks and greenhouse gas emissions on potential microalgae-based biofuel facilities in the United States, Bioresour. Technol. 221 (Dec 2016) 270-275.

[32] M.S. Wigmosta, A.M. Coleman, R.J. Skaggs, M.H. Huesemann, L.J. Lane, National microalgae biofuel production potential and resource demand, Water Resour. Res. 47 (2011).

[33] P.E. Gharagozloo, J.L. Drewry, A.M. Collins, T.A. Dempster, C.Y. Choi, S.C. James, Analysis and modeling of Nannochloropsis growth in lab, greenhouse, and raceway experiments, J. Appl. Phycol. 26 (2014) 2303-2314.

[34] S.J. Edmundson, M.H. Huesemann, The dark side of algae cultivation: characterizing night biomass loss in three photosynthetic algae, Chlorella sorokiniana, Nannochloropsis salina and Picochlorum sp, Algal Res. 12 (2015) 470-476.

[35] http://re.jrc.ec.europa.eu/pvg_tools/en/tools.html.

[36] C. Quiroz-Arita, M.L. Blaylock, P.E. Gharagozloo, T.H. Bradley, T. Dempster, J. McGowen, et al., A dynamic thermal algal growth model for pilot-scale openchannel raceways, Bioresource Technol. Rep. 10 (2020) 100405.

[37] F. Fasaei, J. Bitter, P. Slegers, A. van Boxtel, Techno-economic evaluation of microalgae harvesting and dewatering systems, Algal Res. 31 (2018) 347-362.

[38] T.F. Lopes, C. Cabanas, A. Silva, D. Fonseca, E. Santos, L.T. Guerra, et al., Process simulation and techno-economic assessment for direct production of advanced bioethanol using a genetically modified Synechocystis sp, Bioresource Technol. Rep. 6 (2019) 113-122.

[39] A. Molino, S. Mehariya, A. Iovine, V. Larocca, G. Di Sanzo, M. Martino, et al., Extraction of astaxanthin and lutein from microalga Haematococcus pluvialis in the red phase using $\mathrm{CO}_{2}$ supercritical fluid extraction technology with ethanol as cosolvent, Mar. Drugs 16 (Nov 3 2018).

[40] G. Panis, J.R. Carreon, Commercial astaxanthin production derived by green alga Haematococcus pluvialis: a microalgae process model and a techno-economic assessment all through production line, Algal Res. 18 (2016) 175-190 (2016/09/ 01/).

[41] P. Jian-Liang, W. Hui-Min, C. Chun-Yen, C. Jo-Shu, Extraction of astaxanthin from Haematococcus pluvialis by supercritical carbon dioxide fluid with ethanol modifier, Eng. Life Sci. 12 (2012) 638-647.

[42] J. Li, D. Zhu, J. Niu, S. Shen, G. Wang, An economic assessment of astaxanthin production by large scale cultivation of Haematococcus pluvialis, Biotechnol. Adv. 29 (2011) 568-574 (2011/11/01/).

[43] M.Z. Hauschild, R.K. Rosenbaum, S.I. Olsen, LIfe Cycle Assessment Theory and Practice, (2018)

[44] W. Klöppfer, Background and Future Prospects in Life Cycle Assessment, (2014).

[45] Biondi, N University of Florence, (Personal Communication). 
46] M. Aspen Plus ${ }^{\circledast 10}$ Software (Aspen Technology Inc. Cambridge, USA) ed.

[47] G. Wernet, C. Bauer, B. Steubing, J. Reinhard, E. Moreno-Ruiz, B. Weidema, The ecoinvent database version 3 (part I): overview and methodology, Int. J. Life Cycle Assess. 21 (9) (2016) 1218-1230.

[48] M.Z. Hauschild, Life cycle assessment: goal and scope definition, in: P. The International Academy for (Ed.), CIRP Encyclopedia of Production Engineering, Springer Berlin Heidelberg, Berlin, Heidelberg, 2018, pp. 1-6.

[49] https://www.aqper.com/en/how-much-energy-is-there-in-biogas.

[50] C. Gonzalez-Fernandez, B. Sialve, B. Molinuevo-Salces, Anaerobic digestion of microalgal biomass: challenges, opportunities and research needs, Bioresour. Technol.
198 (2015) 896-906 (2015/12/01/)

[51] J.J. Milledge, B.V. Nielsen, S. Maneein, P.J. Harvey, A brief review of anaerobic digestion of algae for bioenergy, Energies 12 (2019) 1166

[52] C. Ye, D. Mu, N. Horowitz, Z. Xue, J. Chen, M. Xue, et al., Life cycle assessment of industrial scale production of spirulina tablets, Algal Res. 34 (2018) 154-163 (2018/09/01/).

[53] C. Quiroz-Arita, M.L. Blaylock, P.E. Gharagozloo, D. Bark, L. Prasad Dasi, T.H. Bradley, Pilot-scale open-channel raceways and flat-panel photobioreactors maintain well-mixed conditions under a wide range of mixing energy inputs, Biotechnol. Bioeng. 117 (Apr 2020) 959-969. 
Karlsruher Institut für Technologie

\section{Repository KITopen}

Dies ist ein Postprint/begutachtetes Manuskript.

Empfohlene Zitierung:

Onorato, C.; Rösch, C.

Comparative life cycle assessment of astaxanthin production with Haematococcus pluvialis in different photobioreactor technologies.

2020. Algal Research, 50.

doi: $10.5445 / / R / 1000122448$

Zitierung der Originalveröffentlichung:

Onorato, C.; Rösch, C.

Comparative life cycle assessment of astaxanthin production with Haematococcus pluvialis in different photobioreactor technologies.

2020. Algal Research, 50, Article no: 102005.

doi:10.1016/j.algal.2020.102005 